\title{
Experimental Study of Mechanical Behaviour of Renewable Fibre Reinforced Composite Materials Type (Cynara Cardunculus L/Polyester)
}

\author{
Brahim Issasfa $^{1 *}$, Toufik Benmansour ${ }^{1}$, Valéry Valle $^{2}$, Mustapha Bouakba ${ }^{3}$ \\ ${ }^{1}$ Department of Mechanical Engineering, Mentouri University, Constantine 1, PO Box 2476, Constantine 25000, Algeria \\ ${ }^{2}$ Institut Pprime, CNRS, Université de Poitiers, ENSMA, Boulevard Marie et Pierre Curie, BP 30179, Futuroscope \\ Chasseneuil Cedex 86962, France \\ ${ }^{3}$ Department of Mechanical Engineering, Applied Sciences Faculty, Kasdi Merbah University, Ouargla, 1er Novembre Street, \\ Ouargla, Algeria
}

Corresponding Author Email: brahim.issasfa@umc.edu.dz

https://doi.org/10.18280/rcma.300101

Received: 20 August 2019

Accepted: 14 November 2019

\section{Keywords:}

composite materials, biofibres, Cynara cardunculus L, polyester resin, Weibull probability, mechanical characteristics, tensile test

\begin{abstract}
This study is particularly focused on renewable materials of bio-composites. Our work draws on the extraction method and the mechanical characterisation of natural fibres of artichokes (Cyanara cardunculus L) which are produced naturally and in abundance in the northern regions of Algeria particularly so in the north-east. It also draws on the manufacturing of composite with bio-reinforcement models consisting of long fibres of laminated materials of the Cyanara cardunculus $L$ type compiled with unsaturated polyester resin. Standardised sample test-pieces are then drawn from these models so as to carry out tensile and shear tests to evaluate their mechanical behaviour. Additionally, the diversity in characteristics necessitates the use of statistical approaches in order to estimate the proper Weibull parameters of natural fibres, based on a Weibull distribution.
\end{abstract}

\section{INTRODUCTION}

World attention on the health of the planet incessantly threatened by the degradation of the environment under the effect of the lack of concern of economic and industrial operators is becoming increasingly motivated to reduce this risk by encouraging the solution to wards renewable energies, particularly, the use of green materials which offers a double advantage; respect for the environment while abiding by the optimal desired conception criterion robustness combined with cost effectiveness.

Bio materials constitute a question of paramount importance [1]. The future alternative changeover from further conventional supplies of composite materials (carbon fibres, glass fibre, ...) to natural fibres is making headlines with regards to contemporary research oriented towards various industrial fields (automobile, building, aeronautics leisure activities, sports, ...) [2-5]. The improvement of mechanical behaviour and physical characteristics (stress, bending, Young's modulus, Poisson's ratio, density, liquid absorption, hygrothermal, thermal conductivity, lightness ...) are answers targeted by research engineers [6]. The decrease in cost, the increase in life expectancy, reliability and the ease of use are needs that are highly motivating to both parties: constructors and consumers.

Botanically speaking, the artichoke is classed as a nutritive plant intended for food use and particularly the stem and the head [7]. In Algeria artichoke leaves are used in traditional cooking while its roots are used as an important herbal medicine, even though chemists present numerous research titles pertaining to the extraction of chemical and/or pharmaceutical products [8-13].

Natural lignocellulosic fibres such as sisal, coir, jute, rami, pineapple leaves and kenaf can replace glass fibres or other traditional reinforcing composite materials [14-17]. These fibres have different properties such as rigidity [16], resistance to impact [17], flexibility [18] plus they are available in great quantity.

The goal of this work is the extraction of artichoke fibres Cynara cardunculus L, which is naturally available in abundance in the north of Algeria, and their exploitation in the preparation of composites with bio-sourced reinforcements by using polyester resin as a matrix and the artichoke fibre as a strengthening.

NB: Fibres used in this work come from the artichoke existing in the Skikda Wilaya (county) of Algeria.

\section{CYNARA CARDUNCULUS L}

Several types of plants which are a source to various fibres (bio-fibres) are classified as first and second depending on their use. The first plants are developed for their fibre contents whilst the second plants are plants which produce the fibre as a by-product. Jute, hemp, kenaf and coco are examples of secondary plants [19].

There are six types of basic natural fibres. They are classified as follows: Liberian fibres (jute, flax, hemp, ramie, and kenaf), leaves fibres (abaca, sisal and pineapple), grain fibres (coco, cotton and kapok), core fibres (kenaf, hemp and jute), glass fibres and comb (Wheat, Maize, and Rice) and any other type (wood and roots). 
Based on the previous classifications, we find that the artichoke Cynara cardunculus L (Figure 1) produces the four categories of source of fibres; the root, of fruit [20], of the stem [21] and the leaf (Figure 2). In this work, we are interested in fibres that were transplanted from artichoke leaves (Cynara cardunculus L).

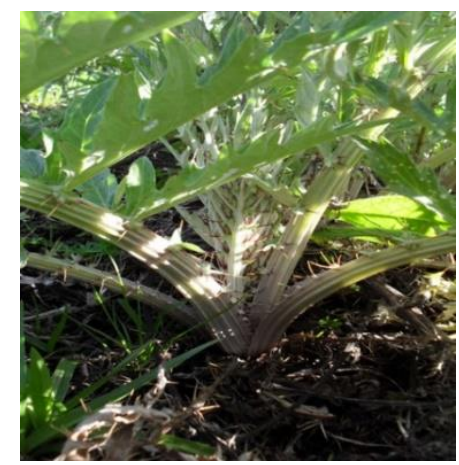

Figure 1. Artichoke cynara cardunculus L

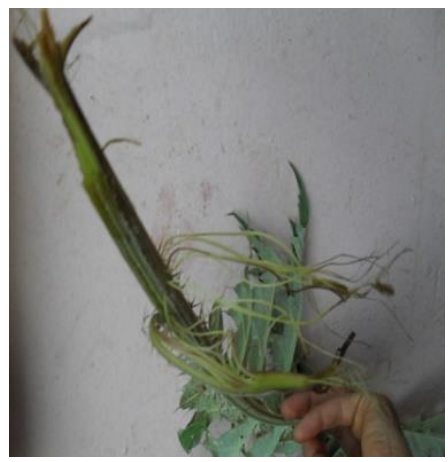

Figure 2. ShrB cardunculus added artichoke leaf

\section{EXTRACTION OF FIBRES}

There are several extraction technics of bio-fibres and amongst them one can choose:

-Retting: A process of rotting of the pectin that links the fibres. This operation can be carried out either in the water (running or not) [21], or on the ground [22]. Today, there are also chemical and enzymatic means of accelerating this process [23]. As for flax, ground retting is more customary due to environmental impacts.

-Grinding: fragmentation of woody parts.

-Scutching: Scutching is the breaking and beating of the straw flax for instance, which separates the textile fibres

-Combing and carding: Disentangling of fibres.

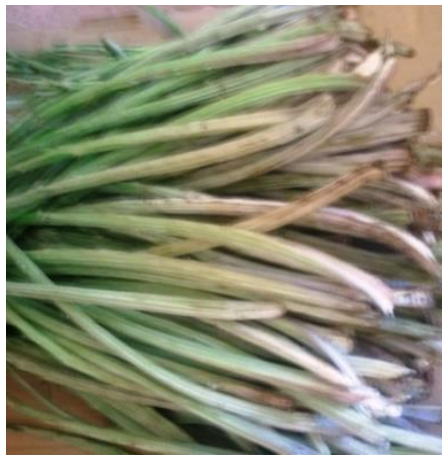

Figure 3. Purified artichoke leaves

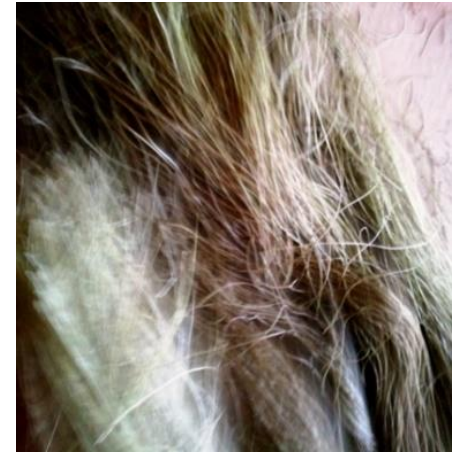

Figure 4. Artichoke leaves fibres

In this work, once they have been cut and cleansed, the leaves (Figure 3 ) are placed on a flexible and spongy ground then they are crush with a hammer until separation of the fibres. Next, the fibres are shaken (Figure 4) until their extraction from the cellulosic paste. Each leaf produces 25 to 38 fibres net, and is capable of reaching $60 \mathrm{~cm}$ in length. It is worth noting, at this point, that this method is environmentally friendly.

\section{MATERIALS AND METHODS}

\subsection{Mechanical characterisation of bio-fibres Cynara cardunculus}

Tensile tests of bio-fibres were carried out by a universal mechanical testing machine (tensile test, bending test, compression test, hardness test ...) according to the standard of ASTM C 1557 - 03. This standard contains a protocol which covers processes of preparation, of assembly and the tests on individual fibres so as to determine the tensile strength and Young's Modulus.

By respecting the following procedure:

* All tests are quasi-static (controlled movement, with a cross head speed of $0.5 \mathrm{~mm} / \mathrm{min}$ ), and were carried out in ambient conditions.

* A cell of $5 \mathrm{KN}$ charge was applied to all fibre specimens. The load displacement curve was recorded during the test.

* The surface in a cross-cut section was evaluated from the measured diameter using an optical microscope in five different places along the length of the sample.

The bio-fibres to be tested are approximately 30 in number and their diameters vary between $200 \mu \mathrm{m}$ and $400 \mu \mathrm{m}$.

The real density of the without treatment fibres of artichoke leaves is $1.00 \mathrm{~g} / \mathrm{cm}^{3}$, measured by the pycnometer process for five samples at ambient temperature. Acetone whose density is equal to $0.875 \mathrm{~g} / \mathrm{cm}^{3}$ is used as a non-polar solvent for measuring the bulk density of fibres and electronic scales were used for weighing the fibres.

This is an interesting result compared to other natural fibres. For instance, sisal fibre density is equal to 1.33-1.5 $\mathrm{g} / \mathrm{cm}^{3}$ and the density of glass fibre is $2.5 \mathrm{~g} / \mathrm{cm}^{3}$ [24].

The use of Artichoke fibres in a volume of $1 \mathrm{~m}^{3}$ saves a complete weight of $330-500 \mathrm{~kg}$ from sisal fibres, and a weight equal to $1500 \mathrm{~kg}$ from glass fibre. 
4.2 Elaboration of test-pieces characterisations of reinforced bio-sourced composite (polyester / fibre of Cynara cardunculus L)

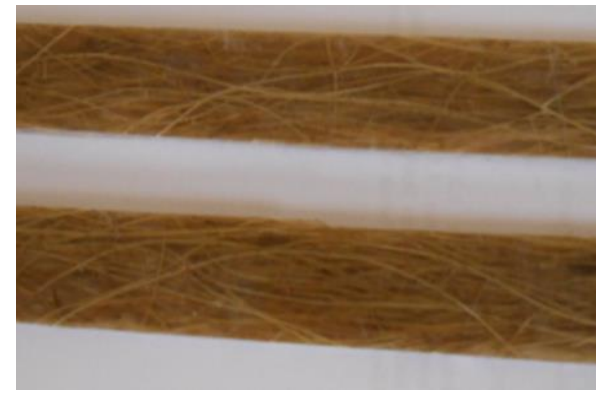

Figure 5. Long reinforced test-piece

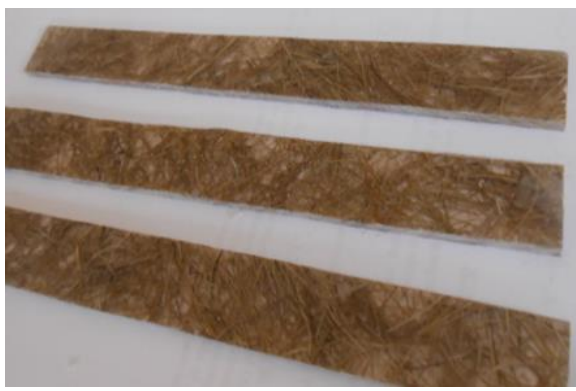

Figure 6. Short reinforced test-piece

The composite studied is a fibre laminate of artichoke and of a polyester resin. The reinforcement is a fibre of Cynara cardunculus L. This is the Skikda variety cultivated in the North-east of Algeria. Orientations of the long fibres are almost unidirectional on the length (Figure 5) and short in a random direction (Figure 6).

The matrix is made of a mixture of polyester resin PRE-64 and of a hardener SR8205 and of an accelerator. During elaboration, the folds are first soaked with resin, then piled up manually and introduced into the mould starting at ambient temperature. The measurements show a fibre rate of $20 \pm 1.4 \%$ in weight calculated using the standard of ASTM
D3171-99 knowing that the fibre density equals $1 \mathrm{~g} / \mathrm{cm}^{3}$.

\subsection{Shear test of a short-beam composite}

The application of short-beam test method is limited to composites with a polymer reinforced matrix with continuous or discontinuous fibres, whose elastic properties are balanced and symmetrical with respect to the longitudinal axis of the beam. This test method allows the determination of the shear strength of the beam of ASTM D2344. The test-pieceis considered as a short beam made from a $4.00 \mathrm{~mm}$ thick flat laminate. The specimen was loaded on three points bending test.

\subsection{Quasi-static tensile tests}

The quasi-static tensile tests carried out are described by the standard ASTM D 3039/D 3039M. They are realised achieve on a servo-electric TE machine with self-tightening grips and at a cross speed of $2 \mathrm{~mm} / \mathrm{min}$. The rectangular testpieces are $250 \mathrm{~mm}$ long, $25 \mathrm{~mm}$ wide and $2.1 \pm 0.5 \mathrm{~mm}$ thick and are equipped with $50 \mathrm{~mm}$ long aluminium heels which have the same width.

\section{RESULTS AND DISCUSSIONS}

\subsection{Microscopic view of the fibre cross section morphology}

In general, bio-fibres morphologies contain empty spaces. Although the Artichoke fibre cross section presents a polygonal shape, and the thickness of the fibre varies a little along the fibre, the cross-sectional area necessary to convert the applied loads to stresses, is calculated by choosing the ruptured section crushed of each fibre. After magnification of the ruptured section viewed under microscope, one can see empty spaces (Figure 7-A). Through the crushing of the section one can decrease the presence of these voids in relation to the material (Figure 7-B).
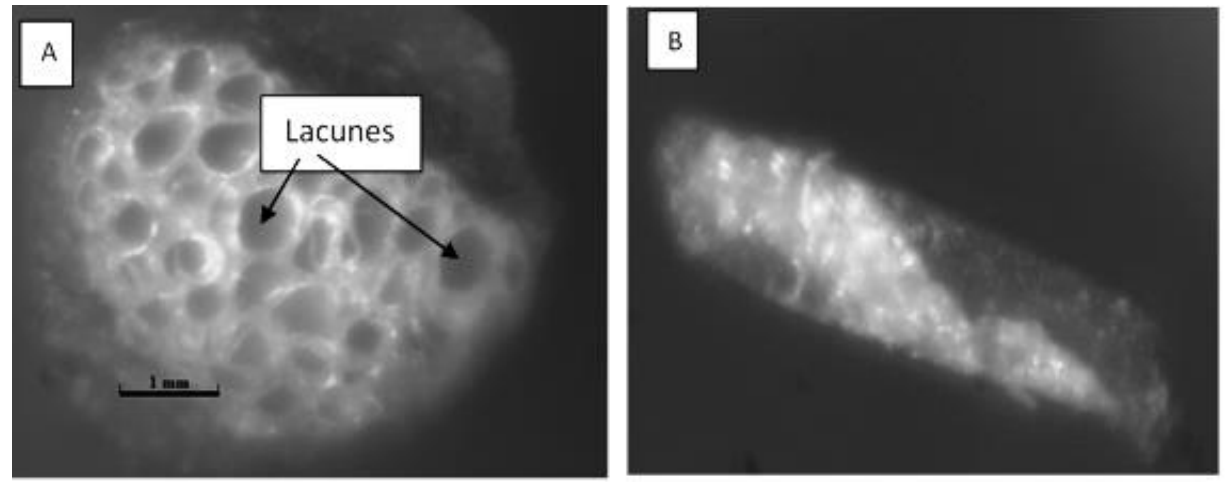

Figure 7. Rupture Section before and after crushing of the section

\subsection{Tensile test of fibres}

Figure 8 presents comparative behaviour curves of tensile stress-strain of artichoke fibres (Cynara cardunculus L) for various diameters without treatment whether it be chemical or thermal. Fibre 17 when subjected to a rupture stress equal to $45 \mathrm{MPa}$, undergoes a strain equal to $0.75 \%$ whilst fibre 19 subjected to a stress equal to $75 \mathrm{MPa}$ undergoes a strain equal to $1.75 \%$. This diversity can be linked mainly to the parameter factors of the test conditions, plant characteristics and measurements. With regards to plant characteristics, the influencing factors on the mechanical behaviour are the plant source, its age, the extraction process of the fibre and the presence of any defects. 


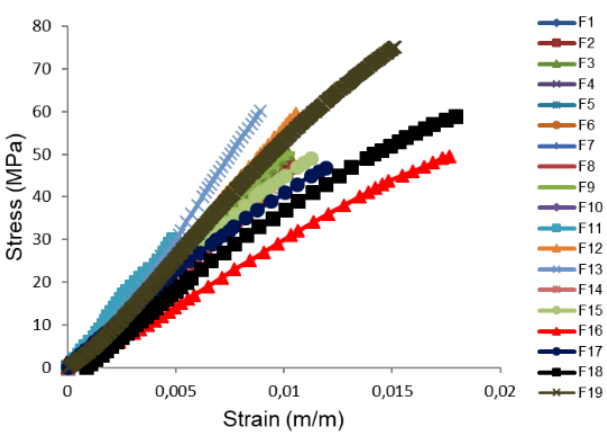

Figure 8. Tensile stress/strain curves of Artichoke fibres Cynara cardunculus L

\subsection{Statistical analysis (Weibull probability)}

Bio-fibres of the artichoke leave, as is customary with most natural fibres, present an important variability in their mechanical properties such as in tensile strength. After Figure 9-A, one finds that rupture-point stress is independent of the increase or decrease of the cross-sectional size. Thus, for instance, at rupture-point, we get section/stress $\left(\mathrm{mm}^{2} / \mathrm{MPa}\right)$ equal to $0.113 / 79,5,0.06 / 46.95$ and $0.2 / 32$. The same applies to Young's Modulus whereby it is not affected by the increase in the cross-sectional size (Figure 9-B). This variability can be explained by the distribution of defects within the fibre or on its surface. Minor differences of microstructure associated with different types of fibres could also be explained by a certain heterogeneity. It is possible to apply Weibull's statistics to describe the statistical distribution of properties which have been used by several authors in order to quantify the degree of variability in natural fibres.

Moreover, it is also clearly visible that the fibres present a fragile behaviour. However, the results of a tensile test on a single filament of small natural fragile fibres are difficult to analyse because of the great dispersion observed in Figure 9C.

Diversity in characteristics necessitates the use of statistical approaches in order to evaluate the average mechanical properties. An example of such an approach is Weibull's distribution function (1).

$$
P(x)=1-\exp \left[-\left(\frac{x}{N}\right)^{\beta}\right]
$$

Tensile properties of fibres were analysed statistically by using one of Weibull's distributions (Eq. 1) with two parameters, position and Weibull distribution $\mathrm{N}$ and $\beta$ respectively.

By simplifying and rearranging Eq. (1) we obtain the following expression:

$$
\ln \left(\ln \left(\frac{1}{1-p}\right)\right)=\ln (x)
$$

Graphically, if by drawing $\mathrm{Y}$ as a function of $\mathrm{X}$, with $Y=$ $\ln \left(\ln \left(\frac{1}{1-p}\right)\right)$ and $X=\ln (x)$, in this work ' $\mathrm{x}$ ' represents the stress variation and Young's Modulus.

The cumulative probability of failure $\mathrm{P}$ of the fibre can be estimated by using Median Rank approximation (Bernard
$\left.P_{i}=\frac{i-0.3}{n+0.4}\right)$, Mean Rank (Herd-Johnson $P_{i}=\frac{i}{n+1}$ ) and modified Kaplan-Meier (Hazen $P_{i}=\frac{i-0.5}{n}$ ) where $i$ represents the number of trials and $n$ is the total number of tests.

Figures 10-A and 10-B show respectively Weibull distribution for stress at rupture-point and Young's Modulus for tensile strength of the fibres of Artichokes leaves. For both mechanical properties whatever the value of Young's Modulus or of the stress, one can see a reasonable approximation of the experimental data.

Table 1 shows four sets of Weibull's statistics generated randomly for values of $\mathrm{N}$ reaching 40 (where $\mathrm{N}$ is the number of tests).

One can observe that all sets of data seem to follow a reasonable rectilinear adjustment, although when $\mathrm{N}$ decreases, the scattering of data around the line increases.

Certain differences can be the result of uncertainties linked to the experiments. Consequently, tensile strength of the artichoke fibre presents a statistical variation, which can be quantified by a unimodal Weibull model.

The four estimators for Weibull's stress distribution offer almost identical adjustment lines $\left(\mathrm{R}^{2}=0.987\right)$. With regards to Weibull's distribution of Young's Modulus the four estimators are well identified, but their concordance with their adjustment line are relatively high and have a coefficient of correlation $\mathrm{R}^{2}$ that varies from 0,9637 à 0,9712 .

Artichoke fibres have a very reasonable mechanical behaviour with which they exist in the literature. Table 2 shows mechanical characteristics of different bio-sourced fibres (made from plants).
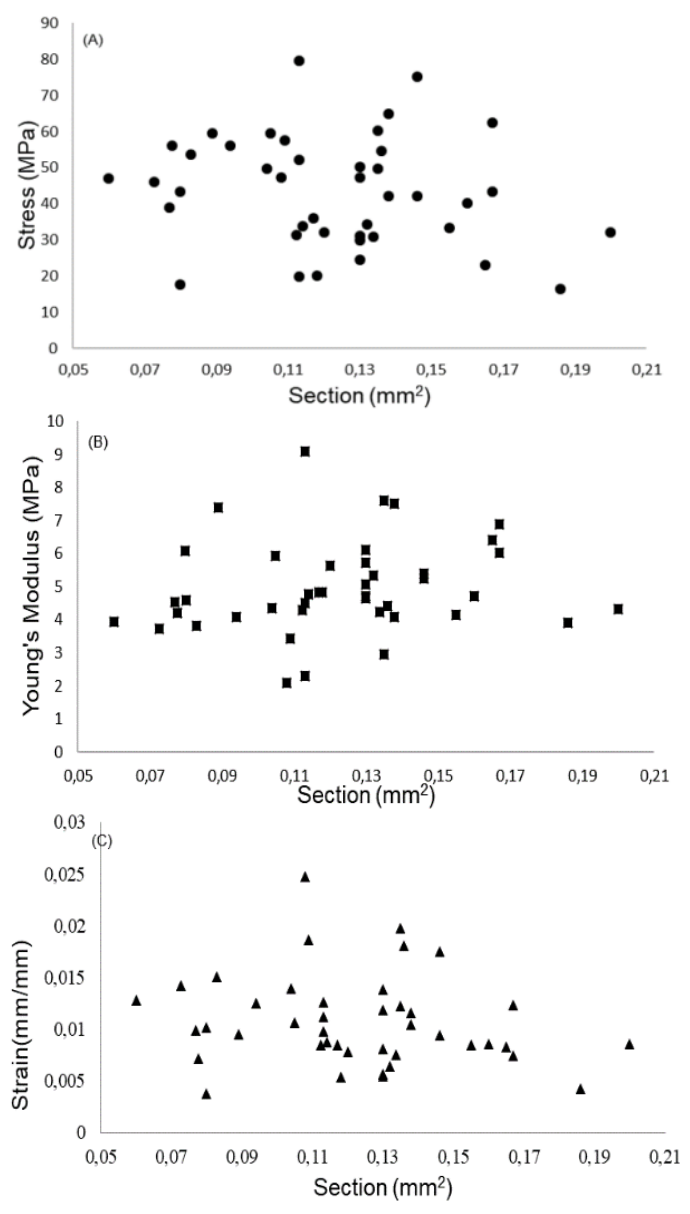

Figure 9. Variation of stress (A), elastic modulus (B) and elongation $(\mathrm{C})$ in function of the section 

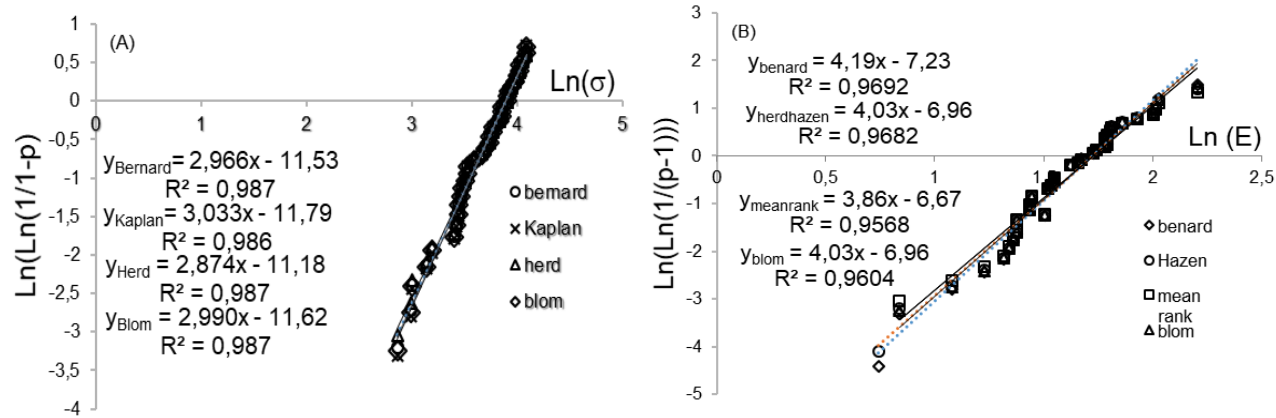

Figure 10. Weibull's distributions of stress (A) and elastic modulus (B) for different estimators

Table 1. Young's Modulus and rupture-point stress after Weibull's criterion

\begin{tabular}{ccccccc}
\hline & $\boldsymbol{\sigma}(\mathbf{M P a})$ & Shape parameter & $\mathbf{R}^{\mathbf{2}}$ & $\mathbf{E}(\mathbf{G P a})$ & Shape parameter & $\mathbf{R}^{\mathbf{2}}$ \\
\hline Bernard & 48,020 & 2,935 & 0,987 & 5,379 & 4,436 & 0,968 \\
Kaplan & 48,145 & 3,008 & 0,986 & 5,364 & 4,618 & 0,971 \\
Herd & 48,534 & 2,839 & 0,987 & 5,398 & 4,232 & 0,963 \\
Blom & 48,2628911 & 2,96189591 & 0,987 & 5,374 & 4,498 & 0,9698 \\
\hline
\end{tabular}

Table 2. Mechanical behaviour of different types of bio-fibres

\begin{tabular}{cccccc}
\hline Fibres & Stress at rupture (MPa) & Young Modulus $(\mathbf{G P a})$ & Strain $(\%)$ & Density $\left(\mathbf{g} / \mathbf{c m}^{\mathbf{3}}\right)$ & Ref \\
\hline Abaca & $760 \pm 160$ & $28.9 \pm 5.8$ & $2.64 \pm 0.68$ & 1.28 & {$[25]$} \\
Bamboo & $262 \pm 75$ & $9.8 \pm 1.6$ & $2.7 \pm 0.7$ & - & {$[26]$} \\
Flax & $800-1500$ & $60-80$ & $1.2-1.6$ & 1.4 & {$[24]$} \\
Hemp & $550-900$ & 70 & 1.6 & 1.48 & {$[27]$} \\
Jute & $393-773$ & 26.5 & 1.9 & 1.48 & {$[28]$} \\
Kenaf & 930 & 53 & 1.6 & - & {$[29]$} \\
Sisal & $400-700$ & $9.4-22$ & $2.0-14$ & $1.33-1.5$ & {$[24]$} \\
Ramie & 88 & 6.3 & 7 & 1.4 & {$[30]$} \\
Banana & $529-914$ & $27-32$ & 5.9 & 1.35 & {$[29]$} \\
Pineapple & 170 & 6,210 & 3 & 1.526 & {$[31]$} \\
Coir & $122.2 \pm 13.3$ & $0.25 \pm 0.09$ & $0.59 \pm 0.056$ & 1.25 & {$[32]$} \\
Curaua & $500-1150$ & 11.8 & $3.7-4.3$ & 1.4 & {$[28]$} \\
Abaca & 400 & 12 & $3-10$ & 1.5 & {$[28]$} \\
Artichoke (leave) & $30-79.4$ & $2.1-9$ & 2.5 & 1.000 & work \\
Artichoke (stem) & - & - & - & $1.579 \pm 0.008$ & {$[21]$} \\
\hline
\end{tabular}

\section{INSTALLATION AND LOADING OF THE SPECIMEN (SHORT BEAM)}

Figure 11-A shows the installation and loading of the testpiece. The span between the two articulations is $\mathrm{s}$, the thickness $t$, the width $b$ and the edge distance are $e$ (excluding articulations). The ratio $\mathrm{b} / \mathrm{t}$ is equal to 5 for the thickness. Note from Figure 11-B the maximum flexure loading $\mathrm{P}_{\mathrm{m}}=1.207 \mathrm{KN}$ correspond deflection of $1.315 \mathrm{~mm}$.

The bending strength of the specimen (short-beam) is calculated by Eq. (3), as follows:

$$
F^{s b s}=0.75 \times \frac{P_{m}}{b \times h}
$$

where,

$F^{\text {sbs }}$ Bending strength of a short beam.

$P_{m}=1.207 \mathrm{~N}$, Maximum load observed during the test.

$b=20 \mathrm{~mm}$ Width of the specimen.

$\mathrm{t}=4 \mathrm{~mm}$ thickness of the specimen.

From the application of Eq. (3) we find the flexure resistance at failure of short beam reached to $11.315 \mathrm{MPa}$ (Artichoke/polyester fibre), installation of specimen (A) and load/deflection curve (B).

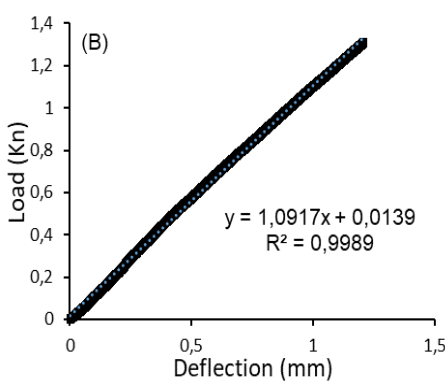

Figure 11. Bending strength test of a short beam 


\section{RESULTS ANALYSIS OF TENSILE TESTS FOR FIBRE, RESIN AND COMPOSITES}

Figure 12 represents the tensile stress/deformation behaviour of (4) types of test-pieces (fibre, composite, resin) which were tested at ambient temperature $24^{\circ} \mathrm{C}$. After the tests it was found that bio-fibres improve by $15 \%$ the resin elasticity. Long fibre reinforcement improves, on one hand, the composite mechanical behaviour whose rupture-point stress reached $29.05 \mathrm{MPa}$. On the other hand, it had decreased the longitudinal deformation by $20 \%$ which means in effect, that the fibre increases the fragility of the material.

Figure 12 shows that reinforcement by short fibres decreases the deformation and the rupture-point stress compared to the reinforcement by long fibres.

Table 3 summarized the results of tensile tests at failure of specimens.

Table 3. Mechanical behaviour of fibre and composites

\begin{tabular}{cccc}
\hline & Fibres & Long reinforcement & Matte reinforcement \\
\hline Strength at rupture (MPa) & 75.07 & 29.05 & 16.39 \\
Young modulus (GPa) & 4.2 & 0.666 & 0.606 \\
Strain (\%) & 1.5 & 4.38 & 2.71 \\
\hline
\end{tabular}

\section{CONCLUSION}

North Algeria is a natural production area of the Artichoke (Cynara cardunculus L) which is very important particularly in the North-East in the surrounding counties of cities like Annaba, Skikda, Guelma, Taraf and Constantine and where this plant is naturally spread and found growing in the wild.

In this work we have examined the extraction of fibres from artichoke leaves with the purpose of evaluating the possibility of using polymer matrixes as reinforcement.

The experimental results are similar to those of other common natural fibres. However, they are inferior to those reinforced by glass fibres, which explains the limited developments of these fibres in the field of composite used in the industry which handles large stresses (force, temperature, ...etc).

The particular increase in the use of green materials can be assimilated to our new structure of artichoke polyester/fibre and its use in the construction industry, either building a/or naval, which work in the production of these fibres.

We may therefore conclude that it is possible for artichoke leaves to be recuperated so as to extract their fibres thus creating an industrial chain, albeit a very localised one, (i.e. from cultivated fields to construction sites), with many advantages, namely:

- From the economic point of view one can mention low costs, a significant reduction in the production time cycles, energy savings in the transformation and the weak density in comparison of other reinforcements.

- From the technical point of view one can cite the mechanical properties almost identical in reinforcements to traditional ones.

- From the ecological point of view, one finds a lowering of the content of materials of fossil origin, the use of a plant with a strong ecological character, the absence of residue after ultimate incineration in the end of its life, the manufacturing of products with a natural aspect, which makes them entirely recyclable.

- Such advantageous characteristics lead more and more industrialists to adopt these new materials.

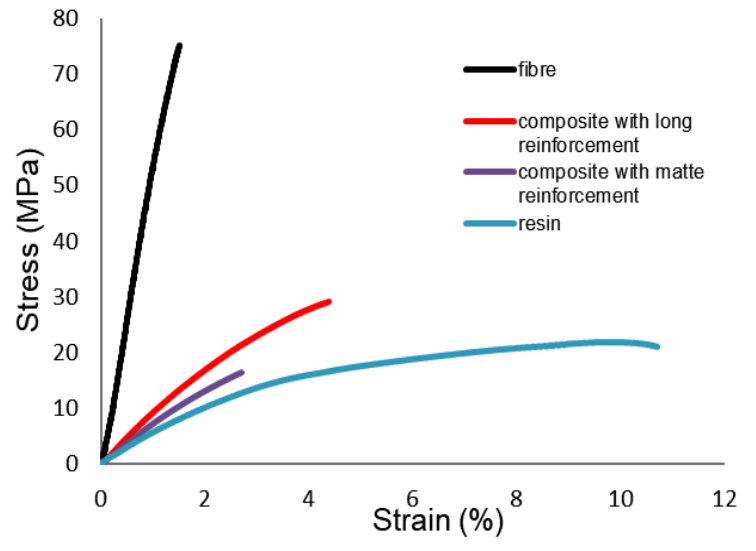

Figure 12. Free tensile behaviour of resin and of composite 
Engineering,

44(1):

$120-127$

https://doi.org/10.1016/j.compositesb.2012.07.004

[5] AL-Oqla, F.M., Sapuan, S.M. (2014). Natural fiber reinforced polymer composites in industrial applications: feasibility of date palm fibers for sustainable automotive industry. Journal of Cleaner Production, 66: 347-354. https://doi.org/10.1016/j.jclepro.2013.10.050

[6] Kabir, M.M., Wang, H., Lau, K.T., Cardona, F., Aravinthan, T. (2012). Mechanical properties of chemically-treated hemp fibre reinforced sandwich composites. Composites Part B: Engineering, 43(2): 159-169.

https://doi.org/10.1016/j.compositesb.2011.06.003

[7] Ruiz-Cano, D., Pérez-Llamas, F., Frutos, M.J., Arnao, M.B., Espinosa, C., López-Jiménez, J.Á., Castillo, J., Zamora, S. (2014). Chemical and functional properties of the different by-products of artichoke (Cynaras colymus L.) from industrial canning processing. Food Chemistry, 160 : 134-140. https://doi.org/10.1016/j.foodchem.2014.03.091

[8] Pistón, M., Machado, I., Branco, C.S., Cesio, V., Heinzen, H., Ribeiro, D., Fernandes, E., Chisté, R.C., Freitas, M. (2014). Infusion, decoction and hydroalcoholic extracts of leaves from artichoke (Cynara cardunculus L. subsp. Cardunculus) are effective scavengers of physiologically relevant ROS and RNS. Food Research International, 64: 150-156. https://doi.org/10.1016/j.foodres.2014.05.078

[9] Shatalov, A.A., Pereira, H. (2014). Dissolving grade eco-clean cellulose pulps by integrated fractionation of cardoon (Cynara cardunculusL.) stalk biomass. Chemical Engineering Research and Design, 92(11): 2640-2648. https://doi.org/10.1016/j.cherd.2014.01.007

[10] Bouriazos, A., IKonomakou, E., Papadogianakis, G. (2014). Aqueous-phase catalytic hydrogenation of methyl esters of Cynara cardunculus alternative lowcost non-edible oil: A useful concept tore solve the food, fuel and environment issue of sustainable biodiesel. Industrial Crops and Products, 52: 205-210. https://doi.org/10.1016/j.indcrop.2013.10.040

[11] Alexandre, A.M.R.C., Diasa, A.M.A., Seabra, I.J., Portugal, A.A.T.G., de Sousa, H.C., Braga, M.E.M. (2012). Biodiesel obtained from supercritical carbon dioxide oil of Cynara cardunculus L. Journal of $\begin{array}{lll}\text { Supercritical } \quad \text { Fluids, } & \text { 58-63. }\end{array}$ https://doi.org/10.1016/j.supflu.2012.03.012

[12] Nomikos, T., Detopoulou, P., Fragopoulou, E., Pliakis, E., Antonopoulou, S. (2007). Boiled wild artichoke reduces postprandial glycemic and insulinemic responses in normal subjects but has no effect on metabolic syndrome patients. Nutrition Research, 27(12):

741-749. https://doi.org/10.1016/j.nutres.2007.09.009

[13] Oliveiraa, I., Gominhob, J., Diberardinoc, S., Duartea, E. (2012). Characterization of cynara cardunculus L. stalks and their suitability for biogas production. Industrial Crops and Products, 40: 318-323. https://doi.org/10.1016/j.indcrop.2012.03.029

[14] Zhan, M., Wool, R.P. (2013). Design and evaluation of bio-based composites for printed circuit board application. Composites Part A: Applied Science and Manufacturing, 47: 22-30. https://doi.org/10.1016/j.compositesa.2012.11.014

[15] Ramesh, M., Palanikumar, K., Reddy, K.H. (2013).
Mechanical property evaluation of sisal-jute-glass fiber reinforced polyester composites. Composites Part B, 48: 1-9. https://doi.org/10.1016/j.compositesb.2012.12.004

[16] Nilsson, H., Galland, S., Larsson, P.T., Gamstedt, K.E., Nishino, T., Berglund, L.A., Iversen, T. (2010). A nonsolvent approach for high-stiffness all-cellulose biocomposites based on pure wood cellulose. Composites Science and Technology, 70(12): 17041712. https://doi.org/10.1016/j.compscitech.2010.06.016

[17] Kaewkuk, S., Sutapun, W., Jarukumjorn, K. (2013). Effects of interfacial modification and fiber content on physical properties of sisal fiber/polypropylene composites. Composites Part B: Engineering, 45(1): 544-549.

https://doi.org/10.1016/j.compositesb.2012.07.036

[18] Jarukumjorn, K., Suppakarn, N. (2009). Effect of glass fiber hybridization on properties of sisal fiberpolypropylene. Composites Part B: Engineering, 40(7): 623-627.

https://doi.org/10.1016/j.compositesb.2009.04.007

[19] Staiger, M.P., Tucker, N. (2008) Natural-fibre composites in structural applications, properties and performance of natural-fibre composites. Woodhead Publishing Series in Composites Science and Engineering, 269-300. https://doi.o,rg/10.1533/9781845694593.2.269

[20] Gominhoa, J., Lourenço, A., Curt, M., Fernandez, J., Pereira, H. (2009). Characterization of hairs and pappi from cynara cardunculus capitula and their suitability for paper production. Industrial Crops and Products, 29(1):

116-125. https://doi.org/10.1016/j.indcrop.2008.04.022

[21] Fiore, V., Valenza, A., Di, B.G. (2011). Artichoke (Cynara cardunculus L.) fibres as potential reinforcement of composite structures. Composites Science and Technology, 71(8): 1138-1144. https://doi.org/10.1016/j.compscitech.2011.04.003

[22] Bouakba, M., Bezazi, A., Boba, K., Scarpa, F., Bellamy, S. (2013). Cactus fibre/polyester biocomposites: Manufacturing, quasi-static mechanical and fatigue characterization. Composites Science and Technology, 74:

150-159. https://doi.org/10.1016/j.compscitech.2012.10.009

[23] Seki, Y., Sarikanat, M., Kutlay, S., Durmuskahya, C. (2013). Extraction and properties of Ferula communis (chakshir) fibers as novel reinforcement for composites materials. Composites Part B: Engineering, 44(1): 517523. https://doi.org/10.1016/j.compositesb.2012.03.013

[24] Li, X., Tabil, L.G., Panigrahi, S. (2007). Chemical treatments of natural fiber for use in natural fiberreinforced composites: a review. J of Polym and the Environ, 15(1): 25-33. https://doi.org/10.1007/s10924006-0042-3

[25] Iucolano, F., Caputo, D., Leboffe, F., Liguori, B. (2015). Mechanical behavior of plaster reinforced with abaca fibers. Construction and Building Materials, 99: 184191. https://doi.org/10.1016/j.conbuildmat.2015.09.020

[26] Zhang, K., Wang, F.X., Liang, W.Y., Wang, Z.Q., Duan, Z.W., Yang, B. (2018). Thermal and mechanical properties of bamboo fiber reinforced epoxy composites. Polymers, $10(6)$ : 608. https://doi.org/10.3390/polym 10060608

[27] Wambua, P., Ivens, J., Verpoest, I. (2003). Natural 
fibres: can they replace glass in fibre reinforced plastics? Composites Science and Technology, 63(9): 1259-1264. https://doi.org/10.1016/S0266-3538(03)00096-4

[28] John, M.J., Anandjiwala, R.D. (2008). Recent developments in chemical modification and characterization of natural fiber reinforced composites. $\begin{array}{lll}\text { Polymer } \quad \text { Composites, } 29(2): & \text { 187-207. }\end{array}$ https://doi.org/10.1002/pc.20461

[29] Malkapuram, R., Kumar, V., Yuvraj, S.N. (2009). Recent development in natural fibre reinforced polypropylene composites. Journal of Reinforced Plastics and Composites, 28(10): 1169-1189. https://doi.org/10.1177/0731684407087759

[30] Ghoushji, M.J., Alebrahim, R., Zulkifli, R., Sulong, A.B., Abdullah, S., Azhari, C.H. (2018). Crashworthiness characteristics of natural ramie/bio- epoxy composite tubes for energy absorption application. Iranian Poly J, 27(8): 563-575. https://doi.org/10.1007/s13726-018-0633-6

[31] Senthilkumar, K., Saba, N., Chandrasekar, M., Jawaid, M., Rajini, N., Othman, Y.A., Siengchin, S. (2019). Evaluation of mechanical and free vibration properties of the pineapple leaf fibre reinforced polyester composites. Construction and Building Materials, 195: 423-431.

https://doi.org/10.1016/j.conbuildmat.2018.11.081

[32] Thomas, S., Woh, Y., Wang, R., Goh, L.K. (2017). Probing the hydrophilicity of coir fibres: Analysis of the mechanical properties of single coir fibres. Procedia Engineering, 200: 206-212. 